\title{
For a Step Change to Curb the Obesity Epidemic
}

\author{
Christian Frois $^{1} \cdot$ Pierre-Yves Cremieux $^{1}$
}

Published online: 12 June 2015

(C) Springer International Publishing Switzerland 2015

\section{Introduction}

Rising obesity levels worldwide have been of increasing public concern since the late 1990s and are now responsible for over one-quarter of total healthcare expenditures in the USA [1]. This special issue of PharmacoEconomics examines a particularly challenging set of issues, with an economic focus: why is the obesity epidemic and its unique burden still growing uncontrolled? how have past efforts to curb it fared? and what other actions are needed to succeed in controlling the epidemic? Contributors to the issue cover a broad range of topics, experience, and perspectives related to obesity. Taken together these articles give some sense of the urgency, challenges, and opportunity for action in this field.

\section{Unchecked Obesity Epidemic and Its Burden}

A number of articles in this special issue examine the obesity epidemic and its burden from different perspectives, to better explore the magnitude and complexity of the problem. Hruby and $\mathrm{Hu}$ [2] provide a review of the epidemiological characteristics and trends of the disease and its burden, e.g., in terms of prevalence of obesity, risk factors, morbidity, mortality, and economic costs. Corica et al. [3] review evidence on the

Pierre-Yves Cremieux

pierre.cremieux@analysisgroup.com

1 Analysis Group, Inc., 111 Huntington Avenue, Tenth Floor, Boston, MA 02199-7668, USA impact of obesity and age on quality of life, highlighting the lesser-studied effect of obesity on the elderly. Cawley et al. [1] and Li et al. [4] use different approaches and data sources to estimate the medical care costs (and savings) associated with weight/body mass index (BMI) — and potential weight loss-for patients with and without diabetes. Allen et al. [5] highlight the impact that obesity has had on Medicare expenditures for certain chronic conditions-such as diabetes, heart disease, hypertension, and hyperlipidemiaover nearly a quarter century (1987-2011). Finally, Gaudette et al. [6] examine the impact of statins on life expectancy and the costs of obesity, and conclude that, despite improvements in life expectancy, statins do not significantly reduce the costs of obesity.

Together, these articles highlight the unique burden and challenge that obesity represents to healthcare systems worldwide. First, the prevalence of obesity is extremely high, with one in three adults worldwide being overweight or obese $[1,2]$. In the USA alone, 80 million adults $(35 \%)$ and 12.7 million children (17\%) suffer from obesity [2, 7, 8]. Second, obesity comes with a large comorbidity burden and is the key underlying driver behind four of the top ten most deadly [2, 5] and expensive [9-11] diseases: ischemic heart disease, cerebrovascular disease (e.g., stroke), hypertension, and diabetes. Notably, obesity accounts for $42.3,30.9,22.4$, and $9.8 \%$ of the increase in the number of cases of diabetes, heart disease, hypertension, and hyperlipidemia, respectively, in the past quarter century [5]. Finally, obesity has a large impact on patient wellness, productivity [12-14], and quality of life [2,3], and is associated with significant costs to healthcare payers and society $[1,4,5,15]$. 


\section{Most Past Interventions Have Failed to Curb Obesity in the Face of Significant Challenges}

Since the first alarm signals were raised about obesity in the early 1990s [16], various interventions have been attempted to curb the epidemic [17]. These interventions have included both prevention and treatment approaches [18]. To date most of the efforts have focused on prevention interventions, including personal responsibility and awareness (e.g., physical exercise/lifestyle interventions, counseling of individuals at risk in primary care [19]), education (e.g., school-based interventions, mass media health promotion campaigns), and environmental control efforts (e.g., food portion/intake control, worksite health promotion interventions, regulation of food advertising to children, compulsory food labeling, tax markups/price promotions) [17-19]. In addition, a few treatment options have been introduced, including both pharmacological and surgical approaches.

Yet, as evidenced by Cecchini and Sassi [18], Baum et al. [20], Chawla et al. [19], and Chawla et al. [21] in this issue, and others [17] elsewhere, interventions have faced and continue to face significant challenges and, to date, have failed to curb obesity. While many interventions appear to have provided some benefits, the gains have often been marginal $[18,22]$. In large part, this appears to be caused by the frequently small scale of the interventions, the complex-and still poorly understood-nature of the disease (with genetic, biological, and environmental factors at play), and significant barriers and challenges facing interventions (e.g., in terms of perception, access/funding, etc.) [23]. Misperception of obesity as a cosmetic or lifestyle issue, rather than a serious health problem, has been a significant hurdle to mobilizing patients, communities, and payers to embrace prevention and treatment initiatives [19, 20]. Many researchers, including those in this issue, note the need for (1) more comprehensive, multi-factorial interventions [17, 22, 24], and (2) treatment as opposed to purely preventive approaches (to both address the needs of the already obese and the limited effectiveness of prevention) [25], as key learnings from past failed experience in obesity prevention/management.

The challenges for new treatment options have been particularly acute. As reported by Baum et al. [20], Finkelstein et al. [26], and Chawla et al. [19], many patients face inadequate access to treatment-pharmacological and surgical-with poor health insurance coverage/ reimbursement, even in rich nations such as the USA and European countries, particularly when patients do not yet experience comorbidities. As noted by Baum et al. [20] and Chawla et al. [21], pharmaceutical innovation in the obesity field has been limited. A poor safety track record of initial pharmaceutical interventions has resulted in cautiousness on the part of regulators in reviewing/granting new drug applications [20]. Current studies assessing the economic benefits/cost effectiveness of obesity treatments $[18,26]$ suffer from limited available data. As a consequence, modeled benefits typically understate the full benefits of obesity reduction. Even clinically effective medications, which result in 5-10\% loss in body weight (the necessary threshold to achieve clinically significant improvements in most risk factors for cardiovascular disease $[27,28])$, have not been fully embraced by patients, as patient expectations for weight loss are generally much more ambitious, while patient adherence can be low [20]. These multiple challenges explain, in part, the underwhelming success of past interventions $[19,20]$ and their disappointing impact on the obesity epidemic [2].

\section{Three Recent Trends Suggest that Obesity and Its Challenges Could Be Curbed}

Despite significant obstacles, there has been progress in the search for effective obesity treatments. Bariatric surgery has emerged as the first (and, so far, only) technology associated with significant success against severe obesity [29-31] and its associated comorbidities [32] for a large proportion of treated patients. The procedure has demonstrated significant cost savings and return on investment for patients with class 3 obesity (i.e., BMI $\geq 40.0$ patients) [33-41] and may be of benefit for other categories of patients [19]. However, its use remains largely confined to the morbidly obese and limited by various obstacles [19, 42]).

Another promising development in the fight against obesity comes from the new wave of approvals for pharmaceutical innovations; four new drugs (lorcaserin, phentermine/topiramate extended release and naltrexone/ bupropion extended release, and liraglutide) were approved in the past 3 years, after over a decade without any approvals for drugs targeting obesity by European and US regulatory agencies [21]. All four drugs hold promise for clinically meaningful weight loss (in excess of $5 \%$, particularly if the intervention is focused on early responders, as recommended by their FDA labels [43-46]).

As documented by the policymaker discussion in this issue [47], another significant area of progress against obesity is the increased stakeholder awareness of the disease and its burden. Policymakers from the USA, Canada, France, China, and Brazil all express great concern at the increase in the size of their populations suffering from obesity and its associated societal burden, and describe some of the measures implemented to help curb obesity in 
their countries [47]. The June 2014 decision of the American Medical Association to label obesity as a disease is also a positive sign of increased awareness among the scientific community and the general public.

\section{Increased Investments to Curb Obesity}

While there are reasons for optimism, the level of investment in obesity treatment remains low relative to the economic and clinical impact of the disease. As shown by Cecchini and Sassi [18] and others [17], initiatives to tackle obesity generally have positive returns, suggesting underinvestment in this area. While in the USA more than a quarter of healthcare costs are driven by obesity [1], investments in obesity treatments are surprisingly low, with only $0.2 \%$ of total healthcare spending accounted for by bariatric surgery costs (author calculations based on figures in [48-50]) and only $0.04 \%$ of total drug expenditure spent on anti-obesity drugs [1].

Ultimately, making headway towards curbing obesity will require a marked change in the effort to tackle the disease. Many commentators suggest that more comprehensive, systemic, multi-factorial programs are needed to answer the obesity epidemic challenge $[2,17,20,21,24$, 47]. While such programs would undoubtedly help, they may not be realistic or achievable without substantial increases in funding. Thus, a step change in investments to curb obesity and its burden is essential. This should include:

- Better access and payer coverage for existing treatment options.

- Increased research and development of effective obesity care and prevention options.

- Development of evidence to guide obesity-related decision making.

- Increased physician and patient advocacy to guide, drive change, and raise awareness of the opportunities and challenges in the fight against obesity.

The recent trend of new anti-obesity interventions remains fragile because of access and reimbursement roadblocks that could curtail continuing innovation [38]. To this day, few US healthcare plans provide coverage for obesity treatments absent morbid obesity and comorbid conditions. Recent pilot schemes suggest that payers are starting to respond to the epidemic. For example, Aetna is introducing in 2015 a program to test the benefits of providing coverage for two obesity therapies (Qsymia and Belviq) in conjunction with lifestyle support for self-insured plan sponsors [51, 52]. The pilot will measure potential improvement in health outcomes, productivity, and medical costs. Such pilots are, by their nature, small relative to patient demand and leave most US patients without coverage. Payers need to make obesity care funding and reimbursement a priority and to ensure that patients in high need of intervention (e.g., BMI >35) are not deterred from treatment by payer restrictions.

Suboptimal investments in $R \& D$ have resulted in part from a challenging regulatory and reimbursement environment (e.g., in the USA) and associated commercial uncertainty $[20,53]$. The complex etiology of obesity (i.e., genetic, environmental, and psychological factors) makes the development of pharmacotherapies and other interventions particularly susceptible to regulatory and reimbursement barriers [2]. In general, pharmacotherapies for obesity can be directed at the following pathways: (1) decreasing energy intake (e.g., appetite suppressants and lipase inhibitors), (2) increasing energy expenditure, (3) modulating fat storage or adipocyte differentiation, or (4) mimicking caloric restriction [54]. However, existing therapies mostly work as appetite suppressants [55] and so does much of the late-stage pipeline of future innovations, despite a number of early-stage options investigating all four pathways [56]. Greater investment in R\&D should help diversify the molecular pathways targeted by antiobesity research.

Another key area where investment has been lacking is the development of information to support stakeholder decision making. Currently there is limited real world information available to researchers and decision makers to probe-from the perspective of payers, employers, physicians and/or patients-the epidemiology, burden, and costs of obesity, the efficacy and cost effectiveness of alternate treatments over time, or the differences between obesity sub-groups. Ideally, such information would provide a nationally representative, unbiased source of data on obesity patients, combining information from payer pharmacy/ medical claims, clinical information from electronic medical records or registries (including information on weight, height, waist circumference, outcomes of interest, etc.), patient reported outcomes, and employer records, etc. [57]. In the USA, to date there is no robust source of obesity epidemiological data beyond that gathered by The National Health and Nutrition Examination Survey (NHANES), and the available registries (e.g., The National Weight Control Registry, NWCR) are of limited scope and provide limited actionable information to payers. This is a far cry from some of the data sources available for cancer (e.g., the Surveillance, Epidemiology, and End Results (SEER) program and other data sources [58]), which have been key to guiding the fight against cancer and assessing the impact of the introduction of advances in prevention, screening, and treatment $[59,60]$.

Despite progress in obesity treatment, a step change is urgently needed to scale the necessary investments to the 
challenge of the disease and its societal burden if the obesity epidemic is to be curbed.

Conflict of interest Christian Frois and Pierre-Yves Cremieux declare no conflicts of interest.

\section{References}

1. Cawley J, Meyerhoefer C, Biener A, Hammer M, Wintfeld N. Savings in medical expenditures associated with reductions in body mass index among US adults with obesity, by diabetes status. Pharmacoeconomics. 2014. doi:10.1007/s40273-0140230-2.

2. Hruby A, Hu FB. The epidemiology of obesity: a big picture. Pharmacoeconomics. 2014. doi:10.1007/s40273-014-0243-x.

3. Corica F, Bianchi G, Corsonello A, Mazzella N, Lattanzio F, Marchesini G. Obesity in the context of aging: quality of life considerations. Pharmacoeconomics. 2014. doi:10.1007/s40273014-0237-8.

4. Li Q, Blume SW, Huang JC, Hammer M, Graf TR. The economic burden of obesity by glycemic stage in the United States. Pharmacoeconomics. 2015. doi:10.1007/s40273-014-0248-5.

5. Allen L, Thorpe K, Joski P. Medicare spending for obesity and selected obesity-related chronic conditions, 1987-2011. Pharmacoeconomics. 2015. doi:10.1007/s40273-015-0284-9.

6. Gaudette É, Goldman DP, Messali A, Sood N. Do statins reduce the health and health care costs of obesity? Pharmacoeconomics. 2015. doi:10.1007/s40273-014-0234-y.

7. Centers for Disease Control and Prevention. Obesity and overweight for professionals: data and statistics-adult obesity. Centers for Disease Control and Prevention. 2014. http://www. cdc.gov/obesity/data/adult.html. Accessed 3 Feb 2015.

8. Centers for Disease Control and Prevention. Obesity and overweight for professionals: childhood obesity facts-prevalence of childhood obesity in the United States, 2011-2012. Centers for Disease Control and Prevention. 2014. http://www.cdc.gov/ obesity/data/childhood.html. Accessed 3 Feb 2015.

9. Kockaya G. What are the top most costly diseases for USA? The alignment of burden of illness with prevention and screening expenditures. Health (Irvine Calif). 2010;02(10):1174-8.

10. Heidenreich PA, Trogdon JG, Khavjou OA, Butler J, Dracup K, Ezekowitz MD, et al. Forecasting the future of cardiovascular disease in the United States: a policy statement from the American Heart Association. Circulation. 2011;123(8):933-44.

11. American Diabetes Association. Economic costs of diabetes in the U.S. in 2012. Diabetes Care. 2013;36(4):1033-46.

12. Kirkham HS, Clark BL, Bolas CA, Lewis GH, Jackson AS, Fisher D, et al. Which modifiable health risks are associated with changes in productivity costs? Popul Health Manag. 2015;18(1): 30-8.

13. Gates DM, Succop P, Brehm BJ, Gillespie GL, Sommers BD. Obesity and presenteeism: the impact of body mass index on workplace productivity. J Occup Environ Med. 2008;50(1): 39-45.

14. Ricci JA, Chee E. Lost productive time associated with excess weight in the U.S. workforce. J Occup Environ Med. 2005; 47(12):1227-34.

15. United Health Foundation, the American Public Health Association, Partnership for Prevention. The future costs of obesity: national and state estimates of the impact of obesity on direct health care expenses. United Health Foundation. 2009. Available from: http://www.nccor.org/downloads/CostofObesityReport-FINAL.pdf. Accessed 26 March 2015.
16. Stamler J. Epidemic obesity in the United States. Arch Intern Med. 1993;153(9):1040-4.

17. Dobbs R, Sawers C, Thompson F, Manyika J, Woetzel J, Child P, et al. Overcoming obesity: an initial economic analysis. McKinsey Global Institute. 2014. http://www.mckinsey.com/ /media/ McKinsey/dotcom/Insights/EconomicStudies/Howtheworldcould betterfightobesity/MGIObesity_Fullreport_November2014.ashx. Accessed 3 Dec 2014

18. Cecchini M, Sassi F. Preventing obesity in the US: impact on health service utilization and costs. Pharmacoeconomics. 2015. doi:10.1007/s40273-015-0301-z.

19. Chawla AS, Hsiao CCW, Romney MC, Cohen R, Rubino F, Schauer P, et al. Gap between evidence and patient access: policy implications for bariatric and metabolic surgery in treatment of obesity and its complications. Pharmacoeconomics. 2015. doi:10. 1007/s40273-015-0302-y.

20. Baum C, Andino K, Wittbrodt E, Stewart S, Szymanski K, Turpin $\mathrm{R}$. The challenges and opportunities associated with reimbursement for obesity pharmacotherapy in the United States. Pharmacoeconomics. 2015. doi:10.1007/s40273-015-0264-0.

21. Chawla A, Carls G, Deng E, Tuttle E. The expected net present value of developing weight management drugs in the context of drug safety litigation. Pharmacoeconomics. 2015. doi:10.1007/ s40273-015-0300-0.

22. Hawkes C, Ahern AL, Jebb SA. A stakeholder analysis of the perceived outcomes of developing and implementing England's obesity strategy 2008-2011. BMC Public Health. 2014;14:441.

23. Gill TP. Key issues in the prevention of obesity. Br Med Bull. 1997;53(2):359-88.

24. Heymann EP, Goldsmith D. Best approaches in the battle against Globesity? Learning lessons from our experience tackling HIVAIDS and tobacco smoking. JRSM Short Rep. 2012;3(7):45.

25. Eyal N. Denial of treatment to obese patients-the wrong policy on personal responsibility for health. Int J Heal policy Manag. 2013;1(2):107-10.

26. Finkelstein EA, Kruger E, Karnawat S. Cost-effectiveness analysis of Qsymia for weight loss. Pharmacoeconomics. 2014. doi:10.1007/s40273-014-0182-6.

27. Wing RR, Lang W, Wadden TA, Safford M, Knowler WC, Bertoni AG, et al. Benefits of modest weight loss in improving cardiovascular risk factors in overweight and obese individuals with type 2 diabetes. Diabetes Care. 2011;34(7):1481-6.

28. Pasanisi F, Contaldo F, de Simone G, Mancini M. Benefits of sustained moderate weight loss in obesity. Nutr Metab Cardiovasc Dis. 2001;11(6):401-6.

29. Colquitt JL, Pickett K, Loveman E, Frampton GK. Surgery for weight loss in adults. Cochrane database Syst Rev. 2014;8: CD003641.

30. Picot J, Jones J, Colquitt JL, Gospodarevskaya E, Loveman E, Baxter L, et al. The clinical effectiveness and cost-effectiveness of bariatric (weight loss) surgery for obesity: a systematic review and economic evaluation. Health Technol Assess (Rockv). 2009;13(41):1-190, 215-357, iii-iv.

31. Levy P, Fried M, Santini F, Finer N. The comparative effects of bariatric surgery on weight and type 2 diabetes. Obes Surg. 2007;17(9):1248-56.

32. Ribaric G, Buchwald JN, McGlennon TW. Diabetes and weight in comparative studies of bariatric surgery vs conventional medical therapy: a systematic review and meta-analysis. Obes Surg. 2014;24(3):437-55.

33. Deitel M. Bariatric surgery is a cost-saving for the healthcare system. Obes Surg. 2005;15(3):301-3.

34. Borisenko O, Adam D, Funch-Jensen P, Ahmed AR, Zhang R, Colpan Z, et al. Bariatric surgery can lead to net cost savings to health care systems: results from a comprehensive European 
decision analytic model. Obes Surg. 2015. doi:10.1007/s11695014-1567-5.

35. Salem L, Jensen CC, Flum DR. Are bariatric surgical outcomes worth their cost? A systematic review. J Am Coll Surg. 2005;200(2):270-8.

36. Karim MA, Clifton E, Ahmed J, Mackay GW, Ali A. Economic evaluation of bariatric surgery to combat morbid obesity: a study from the West of Scotland. Asian J Endosc Surg. 2013;6(3): 197-202.

37. Sánchez-Santos R, Sabench Pereferrer F, Estévez Fernandez S, del Castillo Dejardin D, Vilarrasa N, Frutos Bernal D, et al. Is the morbid obesity surgery profitable in times of crisis? A cost-benefit analysis of bariatric surgery. Cirugía española. 2013;91(8):476-84.

38. Terranova L, Busetto L, Vestri A, Zappa MA. Bariatric surgery: cost-effectiveness and budget impact. Obes Surg. 2012;22(4): 646-53.

39. Chang S-H, Stoll CRT, Colditz GA. Cost-effectiveness of bariatric surgery: should it be universally available? Maturitas. 2011; 69(3):230-8.

40. Finkelstein EA, Allaire BT, Burgess SM, Hale BC. Financial implications of coverage for laparoscopic adjustable gastric banding. Surg Obes Relat Dis. 2011;7(3):295-303.

41. Crémieux P-Y, Ghosh A, Yang HE, Buessing M, Buchwald H, Shikora SA. Return on investment for bariatric surgery. Am J Manag Care. 2008;14(11):e5-6.

42. Ogden CL, Carroll MD, Kit BK, Flegal KM. Prevalence of childhood and adult obesity in the United States, 2011-2012. JAMA. 2014;311(8):806-14.

43. Arena Pharmaceuticals GmbH. BELVIQ (lorcaserin hydrochloride) tablets. In: Fda.gov Product Label. U.S. Food and Drug Administration. 2012. p. 1-28. http://www.accessdata.fda.gov/ drugsatfda_docs/label/2012/022529lbl.pdf. Accessed 3 May 2015.

44. Takeda Pharmaceuticals America Inc. CONTRAVE (naltrexone $\mathrm{HCl}$ and bupropion $\mathrm{HCl}$ ) Extended- Release Tablets. In: Fda.gov Product Label. U.S. Food and Drug Administration. 2014. p. 1-47. http://www.accessdata.fda.gov/drugsatfda_docs/label/ 2014/200063s000lbl.pdf. Accessed 3 May 2015.

45. VIVUS Inc. QSYMIA (phentermine and topiramate extendedrelease) capsules. In: Fda.gov Product Label. U.S. Food and Drug Administration. 2014. p. 1-43. http://www.accessdata.fda.gov/ drugsatfda_docs/label/2014/022580s010s011s012lbl.pdf. Accessed 3 May 2015.

46. Novo Nordisk. SAXENDA (liraglutide [rDNA origin] injection), solution for subcutaneous use. In: Fda.gov Product Label. U.S.
Food and Drug Administration. 2015. p. 1-31. http://www. accessdata.fda.gov/drugsatfda_docs/label/2015/206321s001lbl.pdf. Accessed 3 May 2015.

47. Cremieux P. Policy-makers' view of obesity-related challenges around the world. Pharmacoeconomics. doi:10.1007/s40273-0150290-y.

48. National Institute of Diabetes and Digestive and Kidney Diseases (NIDDK). Bariatric surgery for severe obesity: estimate of bariatric surgery numbers. The American Society for Metabolic and Bariatric Surgery (ASMBS). 2014. http://www.niddk.nih.gov/ health-information/health-topics/weight-control/bariatric-surgerysevere-obesity/Pages/bariatric-surgery-for-severe-obesity.aspx. Accessed 8 April 2015.

49. Finkelstein EA, Allaire BT, Globe D, Dixon JB. The business case for bariatric surgery revisited: a non-randomized case-control study. Folli F, editor. PLoS One. 2013;8(9):e75498.

50. Hartman M, Martin AB, Lassman D, Catlin A. National health spending in 2013: growth slows, remains in step with the overall economy. Health Aff. 2015;34(1):150-60.

51. Aetna. Aetna Promotes Personalized weight-loss options. (Press release). Aetna Inc. 2014. https://news.aetna.com/news-releases/ aetna-promotes-personalized-weight-loss-options/. Accessed 4 May 2015.

52. Aetna tests the weight-loss drug waters with new pilot and pharma collaboration. Drug Benefit News. 2014;15(2).

53. Saadi E, White G. Rewarding innovation in drug development. Am Health Drug Benefits. 2014;7(7):373-4.

54. Misra M. Obesity pharmacotherapy: current perspectives and future directions. Curr Cardiol Rev. 2013;9(1):33-54.

55. Klonoff DC, Greenway F. Drugs in the pipeline for the obesity market. J Diabetes Sci Technol. 2008;2(5):913-8.

56. Rodgers RJ, Tschöp MH, Wilding JPH. Anti-obesity drugs: past, present and future. Dis Model Mech. 2012;5(5):621-6.

57. Gliklich RE, Dreyer NA, Leavy MB, editors. Registries for evaluating patient outcomes: a user's guide. 3rd edn. Rockville: Agency for Healthcare Research and Quality (US); 2014.

58. Greenwald P, Sondik EJ, Young JL. Emerging roles for cancer registries in cancer control. Yale J Biol Med. 1986;59(5):561-6.

59. Hankey BF, Ries LA, Edwards BK. The Surveillance, Epidemiology, and End Results Program: a National Resource. Cancer Epidemiol Biomark Prev. 1999;8(12):1117-21.

60. Cooperberg MR. Progress in management of low-risk prostate cancer: how registries may change the world. Eur Urol. 2015; 67(1):51-2. 